\title{
Translation Revisited: A New Approach
}

\author{
Dr. Misbah M. D. Al-Sulaimaan ${ }^{1}$, Lubna M. Khoshaba ${ }^{2}$ \\ ${ }^{1}$ Prof., Lebanese French University / Erbil \\ ${ }^{2}$ Asst. Lecturer, Lebanese French University / Erbil
}

\begin{abstract}
Generally, translation means replacing a text in one language by another text in another language taking into consideration: (1) lexical elements, (2) syntactic structures, (3) semantic elements, (4) pragmatic elements, (5) literary devices and (6) cultural norms. This research is based on this claim in order to give an effective translation similar to that of the original language text. It is hypothesized that an effective translation cannot be achieved only by resorting to the mentioned elements unless the writer's and/or speaker's intentionality is taken into consideration. This paper aims at re-visiting the basic approaches, methods, procedures of translation, and in the light of what is reviewed, a new approach is suggested in order to help translators as well as interpreters achieve their intentions. The basic finding is that an effective translation is based on the intention of the speaker or writer and to whom he is translating.
\end{abstract}

Keywords- Translation, semantic and pragmatic translation, formal and dynamic equivalence.

\section{INTRODUCTION}

Translation is an incredibly wide notion which can be understood in different ways. For instance, one may talk of translation as a process or a product, and identify such sub-types as literary translation, technical translation, legal translation, journalistic translation, etc. Moreover, while more typically it just refers to the transference of written texts, the term sometimes also includes 'interpreting'. Not surprisingly many formal definitions have also been offered, each of which reflect a particular underlying theoretical model. The linguistic aspects of the translation process have been encapsulated in a large number of definitions, mostly dating from the 1960s or earlier (Shuttleworth and Cowie, 1997). Thus, Catford (1965), for example, defines translation as "the replacement of textual material in one language (SL) by equivalent textual material in another language (TL)". However, as Sager (1993) points out, most older definitions of this type tend to centre around the importance of maintaining some kind of 'equivalence' between ST and TT. Thus for Sager (1993), Jokobson's is in this sense innovative. Jakobson (1966) sees translation in semiotic terms as an interpretation of verbal signs by means of some other languages understanding the translation process as a substitution of "message in one language not for separate code units, but for entire messages in some other languages".Lawendowski (1978) holds the same view when he defined translation as "the transference of meaning from one set of language signs to another set of language signs". An approach based on the importance of preserving the effect of the original is given by Nida and Taber (1982). They say "translation consists in reproducing in the receptor language the closest natural equivalence of the source language message, first in terms of meaning and secondly in terms of style. Nord (1991) defines translation as "the production of a functional target text maintaining a relationship with a given source text that is specified according to the intended or demanded function of the TT. Finally, to reflect the environment in which much professional translation activity takes place, Sager (1993) suggests widening previous definitions by specifying that "translation is an externally motivated industrial activity, supported by information technology, which is diversified in response to the particular needs of this form of communication (for further details, see Neubert, 1991 and Koller, 1995).

From what has been said so far, one can say that translation has been viewed either in terms of finding equivalence or in terms of transference of meaning. In what follows, we will explain these types in some details.

\section{THE CONCEPT OF TRANSLATION}

Translation is not a new comer to the academic scene. It has been widely practised in the course of human history. In present day globalised world, human communication is heavily dependent on translation. The results of this human activity provide a great deal of information about the ancient cultures as well as different present day cultures and help in widening intercultural exchanges. In Bassnett's words, translation, can be seen as the portal through which the past can be accessed. It opens up greater opportunities to remind contemporary readers about lost civilization.

Throughout the history of research into translation, the phenomenon has been variously delimited. In fact, there exists a myriad of definitions of the concept of 'translation'. Some are of an analogical nature, others are of a formal nature; some have a restricted sense, whereas others have abroad sense. Each of these definitions mirrors a specific theoretical tendency 
towardtranslation and reflects the theoretical approach underpinning it.

Catford (1965), for example, argues that translation is an act of replacing linguistic units from a source language to a target language. He wrote, "translation is the replacement of textual material in one language (SL) by equivalent textual material in another language (TL)". What is important for him is to maintain kind of 'equivalence' between the source text (ST) and the target text (TT)

On the same line of thought, Jakobson (1966) sees translation as a linguistic operation which deals with linguistic signs as such. This process can take place between two different languages as well as within the same language. Yet, the verbal signs remain the basis of translation in both cases. Seen from this perspective, translation is restricted and limited to the linguistic material only, i.e. the focus is laid on the linguistic aspects of the translation process. However, Bassnett (1991) categorically deems that translation should be regarded as a series of shifts at both the linguistic and the cultural levels within which a given text is embedded.

Another different view of translation is given by Nida and Taber (1982) who wrote "translating consists in reproducing in the receptor language the closest natural equivalent of the source-language message, first in terms of meaning and secondly in terms of style". Accordingly, they focus on both content and form of the message to reproduce the same effect on the source text.

Bell (1991) seems to have pursued the same line of emphasis on meaning and style in his translation of the definition given by the French theorist "Translation is the expression in another language (or the target language) of what has been expressed in another, (source language), preserving semantic and stylistic equivalences.

The above definitions also confirm the importance of 'equivalence' which underlies the following definitions, among others, given by Catford (1965):" Translation is the replacement of a text in one language by an equivalent text in a second language".

On the other hand, functionalists like Nord (1991) view translation differently. For them, "translation is the production of a functional target text maintaining a relationship with a given source text that is specified according to the intended or demanded function of the target text".

Nord (1991), however, distinguishes between two senses of translation: wide and narrow. For him, "translation is, in a narrow sense, any translational action where a source text is transferred to a target culture and language". According to the form and presentation of the source text and to the correctibility of the target text we distinguish between oral translation (interpreting) and written translation (translation in the narrow sense).

Widening the above definitions, Sager (1993) maintains that translation should reflect the environment in which the professional translation activity takes place. For him "translation is an extremely motivated industrial activity, supported by information technology, which is diversified in response to the particular needs of this form of communication".

In a similar vein, Koller (1995) describes translation as a "text processing activity and simultaneously highlights the significance of equivalence". For him, "translation can be understood as the result of a text-processing activity, by means of which a source-language text between the resulting text in L2 (the target-language text) and the source text L1 (the source-language text) there exists a relationship, or equivalence relation".

To sum up, it is apparent that Nida and Taber's definition may serve as a basis for our concept of translation as a TL product which is as semantically accurate, grammatically correct, stylistically effective and textually coherent as the SL text. In other words, the translator's main attention should not be focused only on the accurate semantic transference of SL message into the TL, but also on the appropriate syntax and diction in the TL, which are explicitly the translator's (not the source author's) domain of activity which displays his true competence. Indeed, according to Wilss (1996), the notion of translation competence, "is aptly assessed in transfer situations that require at least some degree of adaptation to new and challenging textual demands". He describes such situations as "accommodatory situations" which need "structural adjustment" and generally textual manipulation. In tasks with inevitable intricacies of performance his approach to translating expressive, emotive or expository texts in particular is deemed to be creativity-oriented, that is, hermeneutic/manipulation rather than routine-oriented. In the latter approach, SL words are mechanically replaced by their TL equivalents, albeit one-to-one equivalence rarely, if ever, exists between languages.

\subsection{Translation as Process and Product}

Translation can be viewed from different perspectives, that of a 'process' and that of a 'product'. As a process, translation consists of turning a message from one language into another. The transmitted message can be in the form of an expression, an utterance or even a piece of music. Seen from another perspective, translation can be seen as the end product of this process, i.e. the translated text. 
In addition to this twofold division, there exists a third variable, namely that put forward by Bell. He (1991) differentiated between "the abstract concept which encompasses both the process of translating and the product of that process", i.e. translation proper, translating (the process), and a translation (the product).

\subsection{Translation in Terms of Equivalence}

Equivalence is a term used by many writers to describe the nature and the extent of the relationships which exist between SL and TL texts or smaller linguistic units. As such, equivalence is in some senses the intralingual counterpart of synonymy within a single language and sometimes across languages (Shuttleworth and Cowie, 1997). Hence, one should know that Jakobson's (1966) famous slogan "equivalence is difference" highlights the added complications which are associated with it.

The phenomenon of equivalence is indeed complex and its concept is still controversial. Hermans (1995), for example, has described it as a "troubled notion: part of the problem stems from the fact that the term is also standard polysemous English word, with the result that the precise sense in which translation equivalence is understood varies from one translator to another. Catford (1965), for instance, defined translation as the replacement of textual material in one language by the textual material in another language, and argues that one of the central tasks of translation is that of "defining the nature and conditions of translation equivalence". Catford's view of equivalence as something essentially quantifiable - and of translation as simply a matter of replacing each SL item with the most suitable TL equivalent, chosen from a loss of all the limitations of linguistics at that time" (de Beaugrande, 1978). Snell (1995) believes that such a view "presupposes a degree of symmetry between languages, and even distorts the basic problems of translation" in that it reduces the translation process to a mere linguistic exercise, ignoring textual, structural, lexical, cultural and other situational factors, which it is now agreed upon to play an important role in translation. This view has enabled a number of scholars to subdivide the notion of equivalence in various ways. Thus, some have distinguished between the equivalence found at the levels of different "units of translation", whereas others have formulated a number of complete equivalence typologies, such as Nida's (1964) “dynamic and formal equivalence" and Kadmon (2001) total (oneto-one), facultative (one-to-many), approximative (oneto-part) and zero (one-to-one) equivalence. Koller's (1995) is more wide-ranging denotative, connotative, textual-normative (i.e. text type-based), pragmatic and formal-aesthetic equivalence, and Popovic's (1976) linguistic, paradigmatic, stylistic and textual equivalence.
Each of these individual categories of equivalence encapsulated a particular type of ST and TT relationships, although few can be said to be complete in themselves, whereas some (for instance dynamic and formal equivalence) are mutually exclusive. Consequently, the term, which has originally been introduced in order to define translation scientifically, has become increasingly complex and fragmented. Many theoreticians of translation have suggested other terms such as 'similarity', 'analogy' 'correspondence' or 'matching' (cf. Hermans, 1995 and Shuttleworth and Cowie, 1997). Toury (1980) insists on viewing every translation as "a concrete act of performance, and proposes that each TT should be approached via the particular "norms" under which it was produced, arguing that these norms determine "the equivalence" manifested by actual translation" (Toury, 1995). Likewise Newmark (1988) also interpret equivalence on the bas is of each individual text, but unlike Toury (1980), in terms of function and communicative effect. For them, there are no particular features of ST which automatically need to be preserved in the translation process; however, they reserve the term 'equivalence' for this instance in which ST and TT fulfil the same communicative function (for further details, see Wilss, 1994; Turk, 1990; Sturrock, 1991; Pym, 1992; Shuttleworth and Cowie, 1997).

\subsection{Translation in Terms of Transference}

Transference means the "implantation of SL meaning into the TLT (Catford, 1965). This means that the term refers to a process in which an SLitem is used in a TT, but with an SL meaning. This happens when for cultural or other reasons TL has no appropriate equivalent for an SL item and consequently "borrows" the item (Pym, 1992; Shuttleworth and Cowie, 1997). However, true transference is not common, as such borrowed items typically change their meaning, either because the item acquires a foreign feeling or because only one of the total range of meaning which it possesses in SL is transferred.

From what has been said so far, one can come to the conclusion that translation in terms of transference of meaning means conveying the meaning of the SLT to the TLT.

\section{TYPES OF TRANSLATION}

No doubt, the type of translation is determined by the method which is followed. Scholars have suggested many pairs of translation methods such as literal vs. free translation, formal vs. dynamic, semantic vs. communicative, word-for-word vs. sense-for-sense translation, domesticating vs. foreignizing translation, prospective vs. retrospective translation, overt vs. covert translation, among many other pairs. 
The central problem of translating has always been whether to translate literally or freely. The argument has been going on since at least the first century BC. Up to the beginning of the nineteenth century, many writers favoured some kinds of 'free' translation: the spirit, not the letter; the sense not the words; the message rather than the form; the matter not the manner. This was the often revolutionary slogan of writers who wanted the truth to be read and understood. Then at the turn of the nineteenth century, when the study of cultural anthropology suggested that the linguistic barriers were insuperable and that language was entirely the product of culture, the view that translation was impossible gained some currency, and with it that, if attempted at all, it must be as literal as possible. This view culminated in the statements of the extreme 'literalists' Walter Benjamin and Vladimir Nabokov.The argument was theoretical. The purpose of the translation, the nature of the readership, the type of text, was not discussed. Too often, writer, translator and reader were implicitly identified with each other. Now the context has changed, but the basic problem remains.

\subsection{Jakobs on's (1966) Types of Translation}

Jakobson (1966) draws a distinction between three ways of interpreting a verbal sign. It may be translated into other signs of the same language, into another language, or into another code that is nonverbal system of symbols. These three types are as follows:

\subsubsection{Interlingual Translation (Translation Proper)}

This type of translation is an interpretation of verbal signs by means of some other languages. Because of the lack of full equivalence between words of different languages, however, translation from one language into another usually substitutes one entire message for another; hence Jakobson views the process of interlingual translation as a kind of reported speech in which the translator recodes and transmits a message received from another source.

\subsubsection{Intralingual Translation (Rephrasing)}

The process of intralingual translation has been defined as "an interpretation of verbal signs by means of other signs of the same language". This means that intralingual translation is not translation in the strict sense, but rather relies either on the use of synonyms (although these will of course always be approximate, at least to some degree) or circumlocution in order to reword a message in the language of the original. For instance, simplifying a technical text for a non-specialist readership, adapting a classic for a children's audience or producing a version of Chaucer in modern English, are all processes which can be classified as intralingual translation.

\subsubsection{Intersemiotic Translation (Transmutation)}

This type of translation is defined as "an interpretation of verbal signs by means of signs of nonverbal sign systems. Jakobson cites the reinterpretation of verbal art by "music, dance, cinema or painting" as examples of this process. What is "thus" meant by the term is not translation in the standard sense, but transmutation of a verbal message into another medium of expression, or in other words translation in a figurative sense, since the target code is a language "only in a metaphorical manner of speaking".

\subsection{Nida's Types of Equivalence}

Nida(1964) suggests two main types of equivalence. They are as follows:

\subsubsection{Formal Equivalence}

This type of equivalence focuses its attention on the message itself, in both form and content. Formal equivalence is thus the "quality of a translation in which the features of the form of the source text have been mechanically reproduced in the receptor language". This enables the TL reader to grasp and understand as much as possible of the original text.

\subsubsection{Dynamic Equi valence}

This type of equivalence is the quality which characterizes a translation in which "the message of the original text has been so transported into the receptor language that the response of the receptor is essentially like that of the original receptors". In a translation of this kind, one is, therefore, not so concerned with "matching the receptor-language message with the source-language message"; the aim is more to "relate the receptor to modes of behaviour relevant within the context of his own culture".

\subsection{Savory's Types of Translation}

As for Savory (1969), he classifies translation into two main types: literary, and non-literary translation.

\subsubsection{Literary Translation}

This type of translation, according to Savory, comprises the translation of all forms of writing in which the form is not less important than the content. This includes the translation of prose into-poetry, poetry intopoetry, and poetry into prose.

\subsubsection{Non-literary Translation}

This type of translation includes the translation of all scientific and technical material in which the content (or the matter) has the priority over the form (or manner). The translator's main concern is to reproduce the information of the original text with a high degree of accuracy.

\subsection{Newmark's(1988) Types of Translation 3.3.1 Communicative and Semantic Translation}


The concepts of communicative and semantic translation represent Newmark'smain contribution to general translation theory.

1. In communicative as in semantic translation, provided that equivalent effect is secured, the literal word-for-word translation is not only the best, it is the only valid method of translation. There is no excuse for unnecessary 'synonyms' or elegant variations, let alone paraphrases, in any type of translation.

2. Both semantic and communicative translation comply with the usually accepted syntactic equivalents or correspondences for the two languages in question.

3. Communicative and semantic translation may well coincide - in particular, where the text conveys a general rather than a culturally (temporally and spatially) bound message and where the matter is as important as the manner.

4. There is no one communicative or one semantic method of translating a text, these are in fact widely overlapping bands of methods.A translation can be more, or less, semantic, more or less, communicative, even a particular section or sentence can be treated more communicatively or less semantically.

5. The vast majority of texts require communicative rather than semantic translation. Most non-literary writing, journalism, informative articles and books, textbooks, reports, scientific and technological writing, non-personal correspondence, propaganda, publicity, public notices, standardised writing, popular fiction,the run-of-the-mill texts which have to be translated today, but were not translated and in most cases did not exist a hundred years ago, comprise typical material suitable for communicative translation. On the other hand, original expression (where the specific language of the speaker or writer is as important as the content), whether it is philosophical, religious, political, scientific, legal, technical or literary, needs to be translated semantically. A communicative translation may well be a useful introduction, a simplified version, to the semantic translation of such texts.

6. There is no reason why a basically semantic translation should not also be strongly communicative.

7. Meaning is complicated, many-levelled, a 'network of relations' as devious as the channels of thought in the brain. The more communication, the more generalisation; the more simplification, the less meaning. (Newmark is writing against the increasing assumption that all translating is (nothing but) communicating, where the less effort expected of the reader, the better.)

Al-Sulaimaan (1996) summarizes the basic features of semantic and communicative translation by using the following table.

\subsubsection{Features of Semantic and Communicative Translation}

\begin{tabular}{|c|c|c|}
\hline No. & Semantic translation & Communicative translation \\
\hline 1. & It is author-centred. & It is reader-centred. \\
\hline 2. & $\begin{array}{l}\text { It pursues author's thought process Related to } \\
\text { thought. }\end{array}$ & It pursues author's intention. Related to speech. \\
\hline 3. & It is concerned with author as individual. & $\begin{array}{l}\text { It adapts and makes the thought and cultural content of } \\
\text { original more accessible to reader. }\end{array}$ \\
\hline 4. & $\begin{array}{l}\text { It is semanticlly and syntacticllyoriented. } \\
\text { Length of sentences, position and integrity of } \\
\text { clauses, word position, etc. are preserved } \\
\text { whenever possible. }\end{array}$ & $\begin{array}{l}\text { It is effectively oriented. Formal features or original are } \\
\text { sacrificed more readily. }\end{array}$ \\
\hline 5. & It is faithful and more literal. & It is faithful and freer. \\
\hline 6. & It is informative. & It is effective. \\
\hline 7. & $\begin{array}{l}\text { It is usually more awkward, more detailed, } \\
\text { more } \\
\text { complex, but briefer. }\end{array}$ & $\begin{array}{l}\text { It is easily read, more natural, smoother, simpler,clearer, } \\
\text { more direct, more conventional, conforming to particular }\end{array}$ \\
\hline 8. & It is personal. & It is social. \\
\hline 9. & It is source language biased. & It is target language biased. \\
\hline 10. & $\begin{array}{l}\text { It is over-translated:moreconcentrated and } \\
\text { more specific than original. }\end{array}$ & It is under-translated: use of 'hold-all' terms. \\
\hline 11. & It is more powerful. & It is less powerful. \\
\hline 12. & It is always inferior to the original because of & It may be better than original because of gain in force and \\
\hline
\end{tabular}




\begin{tabular}{|c|c|c|}
\hline No. & Semantic translation & Communicative translation \\
\hline & loss of meaning. & clarity, despite loss in semantic content. \\
\hline 13. & It out of time and local place 'eternal'. & It is ephemeral and rooted in its context, 'existential'. \\
\hline 14. & It is wide and universal. & $\begin{array}{l}\text { It is 'tailor-made' or targeted for one category of readership; } \\
\text { does one job, fulfils one particular function. }\end{array}$ \\
\hline 15. & Inaccuracy is always wrong. & $\begin{array}{l}\text { A certain embroidering, a stylistic synonymy, a discreet } \\
\text { modulation is condoned, provided the facts are straight and } \\
\text { the reader is suitably impressed. }\end{array}$ \\
\hline 16. & $\begin{array}{l}\text { The translator has no right to improve or to } \\
\text { correct. }\end{array}$ & $\begin{array}{l}\text { The translator has the right tocorrect and improve the logic } \\
\text { and style of the original, clarify ambiguities, jargons, } \\
\text { normalise bizarre personal usage. }\end{array}$ \\
\hline 17. & $\begin{array}{l}\text { Mistakes in the original should (and must) be } \\
\text { pointed out only in a footnote. }\end{array}$ & The translator can correct mistakes of facts in original. \\
\hline 18. & $\begin{array}{l}\text { The target is a 'true' version, i.e. an exact } \\
\text { statement. }\end{array}$ & The target is a 'happy' version, i.e. a successful act. \\
\hline 19. & $\begin{array}{l}\text { The unit of translating tends to words, } \\
\text { collocations and clauses. }\end{array}$ & The unit of translating tends to sentences and paragraph \\
\hline 20. & $\begin{array}{l}\text { It is applicable to all writings with original } \\
\text { expressiveness. }\end{array}$ & It is applicable to impersonal texts. \\
\hline 21. & Basically the work of translating is an art. & Basically the work of translating is a craft. \\
\hline 22. & It is usually the work of one translator. & It is sometimes the product of a translation team. \\
\hline 23. & $\begin{array}{l}\text { It conforms to the 'relativist' position of } \\
\text { cultural relativity. }\end{array}$ & $\begin{array}{l}\text { It conforms to the 'universalist' position, assuming that } \\
\text { exact translation may be possible. }\end{array}$ \\
\hline 24. & It stresses meaning. & It stresses message. \\
\hline
\end{tabular}

\section{DISCUSSION}

Translation is a kind of secondary communication with both a limiting and an enabling function. It can be defined as a process of replacing a text in one language by an equivalent text in another. It can also be defined in terms of "meaning", "monitoring", "equivalence", "transference", product, intercultural communication, among many other types. The three basic features of translation are thus text, equivalence, and process. Traditionally, one can distinguish between translation as a linguistic act and translation as an intercultural communication.

In the previous sections, we had a glimpse of how complex translation is. This complexity comes about not only because of the problems of pinning down the meaning of an original text, but because of the need to restate that meaning in another text. Different perspectives on translation have focused on different aspects of that process

Given its complexity, translation can, and indeed must be approached from different perspectives, linguistic, cultural, socio-political, literary, purposeoriented. Linguistic perspectives on translation, which focus on the original text, have recently widened their scope considerably-from a concern with lexical and semantic meaning to embracing functional and pragmatic views of language. Scholars who sympathize with the other more psychosocial, more "subjective" pers pective on translation sometimes deny the very relevance of the original text, emphasizing the importance of the relevance and effect of the target text. A focus on variable, culturally conditioned interpretations of texts, and on the purpose of a translation are the most recent, late twentieth century contributions to the field.

A translated text can never be identical to its original; it can only be equivalent to it in certain respects These can be systematized in the form of five equivalence frameworks, not all of which can be fulfilled simultaneously. The choice a translator is forced to make between differently equivalent expressions depends in each individual case on the hierarchy of equivalence demands he sets up for himself, or is asked to follow. Translation is only possible with reference to the concept of equivalence, for there can be no exact transference of meaning across texts in different languages, only an approximation appropriate to purpose. But how far that purpose can be achieved is also dependent on the limits of translatability and the intention of the writer or speaker as well as the intention of the translator and to whom he is translating.

\section{CONCLUSION}

The study arrived at the following conclusions 
1. Using word-to-word translation means that the translator aims at having a contrastive study of the SL text and TL text lexicons.

2. Using literal translation and formal equivalence means that the translator is aiming at having a contrastive study of the syntactic structure and equivalence of the source language text and the target language text.

3. Using semantic translation means that the translator is having a contrastive study of the contextual meaning of the source language and the target language.

4. Using communicative translation means that the translator is after the force of the message as well as the intentionality of the source language writer or the speaker.

5. Using dynamic translation means that the translator is after literary style.

6. Using three translation means that the translator is after the transference of meaning.

7. Using adaptation means that the translator is fully free to give an effective translation taking into account the lexicons, syntactic structure, semantic elements, pragmatic elements, cultural norms and the intentionality of the speaker or the writer.

In the light of our findings and conclusions, our own model of translation will be the following diagram in order to give an effective translation.

\section{REFERENCES}

[1] Bassnett, S. (1991): Translation Studies, London and New York: Routledge.

[2] Bell, R. T. (1991): Translation and Translating: Theory and Practice, London and New York: Longman.

[3] Catford, J. C. (1965): A Linguistic Theory of Translation, London: Oxford University Press.

[4] de Beaugrande, R. (1978): Factors in a Theory Poetic Translation, Assen: Van Gorcum.

[5] Hermans, T. (1995): Translation in Systems: Descriptive and System- Oriented Approaches Explained, Manchester :St. Jerome.

[6] Snell-Hornby, (1995): Translation Studies: An Integrated Approach, Amsterdam \& Philadelphia: John Benjamins.

[7] Jakobson, R. (1966): "On Linguistic Aspects of Translation", in Brower, R.A. (ed.). On Translation, New York: Oxford University Press, A Galaxy Book, pp. 232-239.

[8] Koller, W. (1995): “ The Concept of Equivalence and the Object Translation Studies". Target, 7.
[9] Lawendowski, B. P. (1978): "On Semiotic Aspects of Translation". In: Sebeok, T. A. (ed.): Sight, Sound and Sense, Bloomington: Indian University Press, pp. 264-282.

[10] Neubert, A. (1991): "Models of Translation". In: Tirkkonen-Condit (ed.): Empirical Research in Translation and Intercultural Studies: Selected Papers of the TRANIF Seminar, Savonlinna (1988): Tubingen: Gunter Nar Verlag \{Language in Performance 5\}.

[11] Newmark, P. (1988): A Textbook of Translation, London : Prentice Hall.

[12]Nida, E. and Taber, C. R. (1982): The Theory and Practice of Translation, Leiden: E. J. Brill.

[13]Nida, E. (1964): Toward a Science of Translation: with Special

[14] Reference to Principles and Procedures Involved in Bible

[15] Translation, Leiden: E. J. Brill.

[16]Nord, C. (1991): Text Analysis in Translation: Theory, Methodology and Didactic Application, Amsterdam: Rodopi.

[17] Popovic, A. (1976): " Aspect of Metatext ". In: Canadian Review of Comparative Literature, Vol 3, pp. 225-235.

[18] Pym, A. (1992): "The Relations between Translation and Material Text Transfer". Target, vol. 4, pp. 171-189.

[19] Sager, H-C. (1993): Language Engineering and Translation Consequences, Amsterdam \& Philadelphia: John Benjamins.

[20] Savory, T. (1969): The Art of Translation, Boston: The Writer, Inc.

[21] Shuttleworth, M. and Cowie, M. (1997): A Dictionary of Translation Studies, Manchester: St. Jerome Publishing.

[22] Toury, G. (1995): In Search of a Theory of Translation, Jerusalem: The Porter Institute.

[23] Toury, G. (1995): Descriptive Studies and Beyond, Amsterdam and Philadelphia: John Benjamins.

[24] Wilss, W. (1996): Knowledge and Skills in Translator Behaviour, Amsterdam \& Philadelphia: John Benjamins. 